\title{
HIGH-DOSE INTRAVENOUS IMMUNOGLOBULIN (IVIG) IN RHESUS HAEMOLYTIC DISEASE (RHD)
}

\author{
E. Legnani, L. Corvaglia, A. Aceti, M. Spizzichino, G. Faldella \\ Neonatology and Neonatal Intensive Care Unit, S.Orsola-Malpighi Hospital, University of Bologna, \\ Bologna, Italy
}

Background and aims: RHD is characterized by haemolysis and hyperbilirubinaemia due to Rhincompatibility. Recently, AAP guidelines recommended high-dose IVIg as an alternative to exchange transfusion (EXT).The aim of this study was to compare clinical outcome of RHD patients before and after the introduction of IVIg.

Methods: A chart-review of 88 Coombs-positive RHD patients (1999-2009) was performed. Patients were divided into two groups, treated before (Group A[GA]-n ${ }^{\circ} 35$ ) and after (Group B[GB]-n ${ }^{\circ} 53$ ) the introduction of IVIg, respectively.Number of EXT and RBC transfusions, need and days of permanence of umbilical catheter (UC), duration of hospitalization and phototherapy; maximum bilirubinaemia, changes in bilirubinaemia over time, and morbidity were compared in the two groups.

Results: GB-patients had lower EXT need ( $13 \%$ vs $82 \%$ in GA, $\mathrm{p}=0.000)$, UC need ( $58 \%$ vs $97 \%$, $\mathrm{p}=0.001$ ) and UC days (mean 2.8/patient vs 4.6, $\mathrm{p}=0.001$ ), higher need of $\mathrm{RBC}$ transfusions (mean 0.9/patient vs 0.2 , $\mathrm{p}=0.000$ ), longer hospitalization (mean 12.1 days/patient vs $6.9, \mathrm{p}=0.000$ ) and longer phototherapy (mean 7.6 days/patient vs $4.5, \mathrm{p}=0.000$ ). No significant difference in maximum bilirubinaemia was found; in GBpatients bilirubinaemia overcame neurological-risk value for shorter period (mean 55.4 hours/patients vs 74.6, $\mathrm{p}=0.047$ ). 43.9\% GA-patients had thrombocytopenia, $21.9 \%$ hypocalcaemia, $4.9 \%$ hypomagnesaemia, 19.5\% UC-related complications, and 9.8\% adverse reactions during EXT. Two infants in GB developed NEC.

Conclusions: High-dose IVIg in RHD patients reduced EXT need, UC need and permanence time, and risk of hyperbilirubinaemia-related neurological damage. However, IVIg-treated patients needed longer hospitalization, longer phototherapy, and had increased need of RBC transfusions. 